\title{
A New Method of Quantitative Analysis on Curriculum of Instructional Technology
}

\author{
Mao-juan $\mathrm{LI}^{1}$, Chun WANG ${ }^{2}$ and Fang $\mathrm{ZOU}^{3}$ \\ ${ }^{1}$ Sichuan Agricultural University, Dujiangyan, Sichuan, China \\ ${ }^{2}$ Dongfang Electric Corporation Limited, Chengdu, Sichuan, China \\ ${ }^{3}$ Sichuan Agricultural University, Dujiangyan, Sichuan, China \\ *Jing PU
}

Keywords: Quantitative, Curriculum, Instructional technology.

\begin{abstract}
To improve the assessment of curriculum, this paper proposed a new quantitative analysis method. Firstly, the curriculum was divided into domains, and both domains and courses are investigated. Secondly, an improved expert panel evaluation approach is applied to correct the investigation results. And finally, the investigation of domains and courses are combined to provide a reference to curriculum construction of instructional technology. The method was applied to analysis the curriculum of instructional technology of SICAU, and the result is rational.
\end{abstract}

\section{Introduction}

As a newly rising interdisciplinary field, instructional technology has announced its setting up in China since National Ministry of Education of China listed "Audiovisual Education" in the Specialty Catalogue of Normal University in 1983. After that, instructional technology has developed rapidly in China. Until now, there have been more than 200 universities which hold instructional technology department, and more than 60 of them have the authority of awarding master degree, and six of them have the authority of awarding doctor degree.

With the fast development in China, instructional technology has encountered many problems, especially on the curriculum structure. The essence of instructional technology in China is the application of computer science and audiovisual education, and the real curriculum system and training plan are not yet set up. Therefore, even when students take up even the most basic instructional design work which is the most relevant to instructional technology, they find it's hard to do it well because of the weak skill they mastered[1]. As a result, National Ministry of Education of China has changed the name of Audiovisual Education into Instructional Technology in 1993, and there has been four revisions of curriculum separately in 1983, 1998, 2002 and 2004. However, the courses have too many repeated content and weak logic which has weaken the irreplaceability of instructional technology.

\section{Related Work}

Curriculum Construction. Since the curriculum construction is an essential task for the field of instructional technology, many scholars have researched on it. Xiaohui Chen investigated students studying in instructional technology department from 7 universities in the Northwest of China using questionnaire and found out that the curriculum structure of instructional technology lacks pertinence, which led to the less competitive ability of students [2]. Zhiqing Zhong used interpretive structural model 
(ISM) to analysis the curriculum structure of instructional technology to get the relationship between different courses [3]. Weiyuan Zhang studied the curriculum structure of 6 foreign universities, and gave advices on the curriculum construction of China [4]. However, these researches mainly focus on qualitative analyses which could not provide accurate information and support further careful analyses.

Expert Panel Evaluation. Little work has been done on the quantitative analysis on Curriculum of Instructional Technology while such approach has been widely used in other domains. Qingyuan Lin proposed a correction-compensation method combines the expert evaluation and the assessment of expert's evaluating abilities [5].Chun Wang proposed a fuzzy comprehensive approach to help business crisis early warning [6]. Daohua Pan proposed an evaluation model based on the Kandall coefficient of concordance to determine the reliability parameters to improve evaluation [7].

Contributions. In summary, this paper makes the following contributions: (1)We introduce the corrected expert panel evaluation approach into the curriculum construction of instructional technology. (2) We combine the micro level and macro level of developing curriculum together by separately investigate the weights of the 5 domains of curriculum and each course, and use the weights of 5 domains to correct the weights of courses. (3) We propose an approach to correct student questionnaire to improve the validity.

\section{Method}

In this section, we introduce our new method of quantitative analysis on curriculum construction. First of all, we divide the curriculum of instructional technology into 5 domains. Secondly, we adopt correction-compensation method to evaluate the importance of each 5 domains, and obtain the weight matrix of domain. Thirdly, we carry on a questionnaire investigation on students, and ask them to score the importance of each course, and again adopt the correction-compensation method to obtain the weight matrix of course. Finally, we combine the weight matrix of domain and the weight matrix of course as a reference to curriculum construction.

Classifying the courses. Based on the general consensus [2], we divide the curriculum of instructional technology into 5 domains: the basic theory of instructional technology, information technology education, multi-media technology, educational software engineering and modern distance education based on review and analysis of literatures. In this paper, we take the curriculum of Instructional Technology Department of Sichuan Agricultural University (SICAU) as research object, and invite experts to classify the courses into 5 domains. The result has been processed using voting method. And the result is shown in Table 1.

The Expert Evaluation Approach. The expert panel evaluation approach is a main approach in comprehensive evaluation. The approach bases on the knowledge and experiences of experts and intuition thinking, which make it simple and could be easily carried out. Despite these benefits of the approach, the result tends to be influenced by experts' subjective preferences and their evaluating abilities. As Jifa Gu mentioned in his paper, the expert panel evaluation not only includes experts evaluating, but also includes the accession of valuators [8]. Expert panel evaluation approach includes scoring method, classification and weighted average method, and none of them has considered the assessment of valuator. 
Table 1. The Catalog of Curriculum of Instructional Technology

\begin{tabular}{|c|c|c|}
\hline Domains & \multicolumn{2}{|c|}{ Courses } \\
\hline $\begin{array}{l}\text { Basic Theory } \\
\text { of } \\
\text { Instructional } \\
\text { Technology } \\
\text { C1 }\end{array}$ & $\begin{array}{l}\text { A Survey into Instructional Technology } \\
\text { General Psychology } \\
\text { Pedagogic } \\
\text { Educational Psychology }\end{array}$ & $\begin{array}{l}\text { Instructional Technology } \\
\text { Instructional Design } \\
\text { Advertising design and production }\end{array}$ \\
\hline $\begin{array}{c}\text { Information } \\
\text { Technology } \\
\text { Education C2 }\end{array}$ & $\begin{array}{l}\text { Network Education Application } \\
\text { Multimedia Courseware Design }\end{array}$ & \\
\hline $\begin{array}{l}\text { Multi-media } \\
\text { Technology } \\
\text { C3 }\end{array}$ & $\begin{array}{l}\text { Art Constitution } \\
\text { Animated Characters and Scene Design } \\
\text { Television Program Production } \\
\text { 2-DAnimation Design and Production } \\
\text { Computer Graphics and Image Processing }\end{array}$ & $\begin{array}{l}\text { Digital Audio and Video } \\
\text { Technology } \\
\text { Flash Programming } \\
\text { Web Design and Production } \\
\text { 3D Animation Design Technology }\end{array}$ \\
\hline $\begin{array}{l}\text { Educational } \\
\text { Software } \\
\text { Engineering } \\
\text { C4 }\end{array}$ & $\begin{array}{l}\text { C ++ Programming } \\
\text { Web Programming Foundation } \\
\text { Principles of Database Systems } \\
\text { Java Programming }\end{array}$ & $\begin{array}{l}\text { SQL Database System } \\
\text { Data Structure } \\
\text { Software Engineering }\end{array}$ \\
\hline $\begin{array}{c}\text { Modern } \\
\text { Distance } \\
\text { Education C5 }\end{array}$ & $\begin{array}{l}\text { Computer Network } \\
\text { Networking Technology }\end{array}$ & \\
\hline
\end{tabular}

We denote the evaluation set by $\mathrm{E}=\{$ Very Important, Important, Normal, Not Important, Not Very Important $\}$. Experts evaluate the importance of domains, and choose a value from $\mathrm{E}$ for each domain. For the convenience of further data processing, we transfer $\mathrm{E}=\{$ Very Important, Important, Normal, Not Important, Not Very Important $\}$ into $C=\{1,0.8,0.6,0.4,0.2\}$ to normalize the values.

Step 1.

Collect the evaluations of $n$ experts with $m$ evaluation indices. Let $B_{k j}$ denotes the evaluation of the expert $k$ on evaluation index $j$, and $B_{k j}$ takes a value from set $E$. After that we transfer $B_{k j}$ into $C_{k j}$, and $C_{k j}$ takes a value of set $C$.

Step 2.

Calculate the arithmetic mean $\mathrm{C}_{\mathrm{j}}$ of evaluation values.

$$
\overline{C_{j}}=\frac{1}{n} \sum_{k=1}^{n} C_{k j}(j=1,2, \ldots, m)
$$

Where $\mathrm{n}$ is the total number of experts.

Step 3.

Calculate the evaluation variance of each expert $\mathrm{S}_{\mathrm{k}}{ }^{2}$.

$$
S_{k}^{2}=\frac{1}{m-1} \sum_{j=1}^{m}\left(C_{k j}-\overline{C_{j}}\right)^{2}(i=1,2, \ldots, n) .
$$

By the statistical theory, we know $\mathrm{S}_{\mathrm{k}}^{2}$ is an unbiased estimate of value $\sigma_{\mathrm{k}}^{2}$.

Step 4.

Get the weights of the evaluation of the ability of each expert.

$$
a_{k}=\left[S_{k}^{2} \cdot \sum_{k=1}^{n} \frac{1}{S_{k}^{2}}\right]^{-1}(i=1,2, \ldots, n) .
$$

Where $a_{k}$ is the weight of the evaluation of the ability of expert k. Step 5. 
Get the capability of each expert $e^{k}$, which denotes how high the expert's evaluation is coherence with the evaluation of expert panel.

$$
e^{k}=\frac{a_{k}}{\bar{a}}
$$

Where $\bar{a}=\frac{1}{n}$.

Step 6.

Then we obtain membership matrix $\mathrm{R}$

$$
R=\left[\begin{array}{ccc}
r^{11} & \mathrm{~K} & r^{1 i} \\
\mathrm{M} & \mathrm{O} & \mathrm{M} \\
r^{j 1} & \Lambda & r^{j i}
\end{array}\right]
$$

Where $r_{j i}=\frac{d_{j i}}{d}$,

And $\mathrm{d}_{\mathrm{ji}}$ is the summary of evaluation abilities $\mathrm{e}^{\mathrm{k}}$ of all experts that give $\mathrm{i}$ evaluation value to $\mathrm{j}$ evaluation index, and $\mathrm{d}$ is the summary of evaluation abilities $\mathrm{e}^{\mathrm{k}}$ of all experts.

Step 7.

Let weight matrix $\mathrm{W}=\left\{\mathrm{a}_{\mathrm{k}}\right\}$, and the comprehensive evaluation result could be denoted as:

$$
S=W R \text {. }
$$

Correcting the student's evaluation on the importance of courses. Students' opinions on courses could to some extend reflect the role of each courses and demand of society. Therefore, when a certain university is deciding the curriculum structure of a subject, students' opinions should be considered. However, students' opinions are also influenced by other factors such as personal preferences. And it is also widely acknowledged that students are easily to have biases on some courses because of short sight. To solve these problems, we propose a novel approach which corrects the student's evaluation by expert evaluation result.

Let $C s_{k j}$ to be the evaluation of student k on course $\mathrm{j}$, and according to the expert evaluation approach we proposed, the comprehensive evaluation result $S s=W s R s$ could be obtained, where $W s$ is the weight matrix and $R s$ is the membership matrix.

Then the corrected student's evaluation could be denoted as:

$$
S m=S \cdot S s
$$

Where $S$ is the evaluation of expert panel, and $S s$ is the evaluation of student.

\section{Data Analysis}

Expert Panel Evaluation. 20 experts are invited to evaluate the importance of each catalog of instructional technology curriculum, and the results are marked using evaluation set E. By using expert panel evaluation approach just mentioned above, the evaluation results are obtained. The evaluations of experts are shown in Table 2, and the evaluation variance, deviation and weight of each expert are shown in Table 3. 
Table 2. Expert Panel Evaluation on Curriculum of Instructional Technology of SICAU

\begin{tabular}{|c|c|c|c|c|c|}
\hline Expert & $\begin{array}{c}\text { Basic Theory } \\
\text { of } \\
\text { Instructional } \\
\text { Technology } \\
\text { Ck1 }\end{array}$ & $\begin{array}{c}\text { Information } \\
\text { Technology } \\
\text { EducationCk2 }\end{array}$ & $\begin{array}{c}\text { Multi-media } \\
\text { Technology } \\
\text { Ck3 }\end{array}$ & $\begin{array}{c}\text { Educational } \\
\text { Software } \\
\text { Engineering } \\
\text { Ck4 }\end{array}$ & $\begin{array}{c}\text { Modern } \\
\text { Distance } \\
\text { Education } \\
\text { Ck5 }\end{array}$ \\
\hline 1 & 0.6 & 0.6 & 1 & 0.8 & 0.4 \\
\hline 2 & 0.8 & 0.4 & 1 & 0.8 & 0.6 \\
\hline 3 & 0.6 & 0.6 & 1 & 0.8 & 0.6 \\
\hline 4 & 0.8 & 0.6 & 0.8 & 0.8 & 0.4 \\
\hline 5 & 0.8 & 0.6 & 1 & 1 & 0.6 \\
\hline 6 & 0.8 & 0.4 & 1 & 0.8 & 0.6 \\
\hline 7 & 0.8 & 0.6 & 1 & 0.8 & 0.4 \\
\hline 8 & 0.6 & 0.6 & 1 & 1 & 0.6 \\
\hline 9 & 0.8 & 0.6 & 1 & 1 & 0.6 \\
\hline 10 & 0.8 & 0.6 & 1 & 0.8 & 0.6 \\
\hline 11 & 0.8 & 0.6 & 0.8 & 0.8 & 0.6 \\
\hline 12 & 0.8 & 0.6 & 1 & 1 & 0.6 \\
\hline 13 & 0.6 & 0.6 & 1 & 0.8 & 0.6 \\
\hline 14 & 0.8 & 0.6 & 1 & 1 & 0.6 \\
\hline 15 & 0.8 & 0.6 & 1 & 0.8 & 0.6 \\
\hline 16 & 0.8 & 0.6 & 1 & 0.8 & 0.4 \\
\hline 17 & 0.6 & 0.4 & 1 & 0.8 & 0.6 \\
\hline 18 & 0.8 & 0.6 & 1 & 0.8 & 0.6 \\
\hline 19 & 0.8 & 0.6 & 0.8 & 0.8 & 0.4 \\
\hline 20 & 0.8 & 0.6 & 0.8 & 0.8 & 0.6 \\
\hline
\end{tabular}

Table 3. The Evaluation Variance, Deviation and Weight of Each Expert

\begin{tabular}{|l|l|l|l|}
\hline Expert & Evaluation Variance & Deviation of Expert & Weight \\
\hline 1 & 0.0125 & -0.056 & 0.025893 \\
\hline 2 & 0.0095 & -0.016 & 0.03407 \\
\hline 3 & 0.0075 & -0.016 & 0.043156 \\
\hline 4 & 0.0135 & -0.056 & 0.023975 \\
\hline 5 & 0.0075 & 0.064 & 0.043156 \\
\hline 6 & 0.0095 & -0.016 & 0.03407 \\
\hline 7 & 0.0075 & -0.016 & 0.043156 \\
\hline 8 & 0.0125 & 0.024 & 0.025893 \\
\hline 9 & 0.0075 & 0.064 & 0.043156 \\
\hline 10 & 0.0025 & 0.024 & 0.129467 \\
\hline 11 & 0.0085 & -0.016 & 0.038078 \\
\hline 12 & 0.0075 & 0.064 & 0.043156 \\
\hline 13 & 0.0075 & -0.016 & 0.043156 \\
\hline 14 & 0.0075 & 0.064 & 0.043156 \\
\hline 15 & 0.0025 & 0.024 & 0.129467 \\
\hline 16 & 0.0075 & -0.016 & 0.043156 \\
\hline 17 & 0.0145 & -0.056 & 0.022322 \\
\hline 18 & 0.0025 & 0.024 & 0.129467 \\
\hline 19 & 0.0135 & -0.056 & 0.023975 \\
\hline 20 & 0.0085 & -0.016 & 0.038078 \\
\hline
\end{tabular}

And we could obtain the comprehensive evaluation result $\mathrm{S}$ by Eq. 4, Eq. 5 and Eq. 6. 


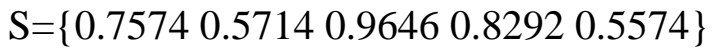

Correcting the Student Evaluation. Questionnaire investigation was carried out on senior students of the university. Since in this research Likert Five Scale was adopted to evaluate, the respondents should choose an item from 'very important', 'important', 'normal', 'not important' and 'very not important'. 84 valid questionnaires were retrieved, and Alpha reliability coefficient is measured to guarantee the reliability of investigation data. Under normal circumstances, it is considered to be a high internal reliability of the scale if the reliability coefficient is between 0.7 to 1 , and the data should be abandoned if the reliability coefficient is under 0.7 .

Table 4. Students' Evaluation Results and Corrected Students' Evaluation

\begin{tabular}{|c|c|c|c|c|}
\hline No. & Course & $\begin{array}{l}\text { Students' } \\
\text { Evaluation } \\
\left(\mathrm{S}_{\mathrm{s}}\right)\end{array}$ & $\begin{array}{l}\text { Expert } \\
\text { Evaluation(S) }\end{array}$ & $\begin{array}{l}\text { Corrected } \\
\text { Students' } \\
\text { Evaluation } \\
\end{array}$ \\
\hline 1 & \multirow{7}{*}{$\begin{array}{l}\text { A Survey into Instructional } \\
\text { Technology } \\
\text { General Psychology } \\
\text { Pedagogic } \\
\text { Educational Psychology } \\
\text { Instructional Technology } \\
\text { Instructional Design } \\
\text { Advertising design and production }\end{array}$} & 3.10 & \multirow[t]{7}{*}{0.7574} & 2.35 \\
\hline 2 & & 3.21 & & 2.43 \\
\hline 3 & & 3.65 & & 2.77 \\
\hline 4 & & 3.73 & & 2.82 \\
\hline 5 & & 3.19 & & 2.42 \\
\hline 6 & & 3.96 & & 3.00 \\
\hline 7 & & 4.37 & & 3.31 \\
\hline 8 & \multirow{2}{*}{$\begin{array}{l}\text { Network Education Application } \\
\text { Multimedia Courseware Design }\end{array}$} & 3.47 & \multirow[t]{2}{*}{0.5714} & 1.98 \\
\hline 9 & & 3.85 & & 2.20 \\
\hline 10 & \multirow{9}{*}{$\begin{array}{l}\text { Art Constitution } \\
\text { Animated Characters and Scene } \\
\text { Design } \\
\text { Television Program Production } \\
\text { 2-DAnimation Design } \\
\text { Computer Graphics and Image } \\
\text { Processing } \\
\text { Digital Audio and Video } \\
\text { Technology } \\
\text { Flash Programming } \\
\text { Web Design and Production } \\
\text { 3D Animation Design Technology }\end{array}$} & 4.05 & \multirow[t]{9}{*}{0.9646} & 3.91 \\
\hline 11 & & 4.09 & & 3.95 \\
\hline 12 & & 3.52 & & 3.40 \\
\hline 13 & & 4.07 & & 3.92 \\
\hline 14 & & 4.13 & & 3.99 \\
\hline 15 & & 3.20 & & 3.09 \\
\hline 16 & & 3.61 & & 3.48 \\
\hline 17 & & 3.82 & & 3.69 \\
\hline 18 & & 3.79 & & 3.66 \\
\hline 19 & \multirow{7}{*}{$\begin{array}{l}\text { C ++ Programming } \\
\text { Web Programming Foundation } \\
\text { Principles of Database Systems } \\
\text { Java Programming } \\
\text { SQL Database System } \\
\text { Data Structure } \\
\text { Software Engineering }\end{array}$} & 3.62 & \multirow{7}{*}{0.8292} & 3.00 \\
\hline 20 & & 3.82 & & 3.17 \\
\hline 21 & & 3.68 & & 3.05 \\
\hline 22 & & 3.38 & & 2.80 \\
\hline 23 & & 3.47 & & 2.87 \\
\hline 24 & & 3.12 & & 2.59 \\
\hline 25 & & 3.63 & & 3.01 \\
\hline 26 & \multirow{2}{*}{$\begin{array}{l}\text { Computer Network } \\
\text { Networking Technology }\end{array}$} & 3.67 & \multirow[t]{2}{*}{0.5574} & 2.05 \\
\hline 27 & & 3.76 & & 2.09 \\
\hline
\end{tabular}

SPSS is used to do this work, and the Alpha reliability coefficient of the data in this investigation is 0.763 , which means this data is considered to be credible.

The students' evaluations $S_{\mathrm{s}}$ and expert evaluation $S$ are shown in table 4 . We could easily get the corrected student evaluation by Eq. $7 \mathrm{Sm}=S \cdot S s$, and the result is also shown in Table 4. 


\section{Summary}

Undergraduate curriculum development generally has two levels: the micro level and macro level. In this paper, we analyze the curriculum construction from the micro-level and macro-level by using expert evaluation and a five-point Likert scale questionnaire respectively. The study can provide a reference for instructional technology curriculum evaluation for general universities to help them on regular curriculum evaluation, and to find and to correct the problems. But it only proposed an overall idea for the research. In practice, universities should consider their own situation, and combine with social needs to make better decision.

\section{References}

[1]Yang Xiaohong, Liang Li. The Reform Thinking of the Training Objectives of Educational Technology [J]. Educational Research, 1999, 03.

[2] Chen Xiaohui, Tao Shuangshuang and Sun Jinghua. Investigation and Analysis for Undergraduate Educational Technology Curriculum $[\mathrm{J}]$. China Educational Technology, 2004, 9: 26-30.

[3] Zhong Zhiqiang and Han Ying. An Analysis and Discussion on Undergraduate Curriculum System of Educational Technology by ISM [J]. China Medical Education Technology,2008, 06: 522-525.

[4] Zhang Weiyuan. International Comparation of Distance Education and Educational Technology Curriculum [J]. China Distance Education, 2005, Vol (04S): 8-11.

[5] Lin Yuanqing. A Correction - Compensation Method of Expert Panel Evaluation and its Application [J]. Science Research, 1998, 4: 69-75.

[6] Wang Chun and Chen Youling. Fuzzy Comprehensive Evaluation Method in Enterprise Crisis Alert Application [J]. Industrial Engineering and Management, 2007, 02: 85-87.

[7] Pan Daohua. An Evaluation Approach Based on Uncertainty Reasoning in Expert Panel Reliability [J]. Science in China people, 2015, 12.

[8] Gu Jifa. A Survey on Evaluation Methods [C] // Scientific Decision-Making and System Engineering - Proceedings of the Sixth Annual Meeting of China System Engineering Society, 1990. 